\title{
Assembly and function of a TCR $\alpha$ enhancer complex is dependent on LEF-1-induced DNA bending and multiple protein-protein interactions
}

\author{
Klaus Giese, ${ }^{1}$ Chris Kingsley, Jessica R. Kirshner, and Rudolf Grosschedl \\ Howard Hughes Medical Institute, Departments of Microbiology and Biochemistry, University of California, \\ San Francisco, California 94143-0414 USA
}

In this study we examine the molecular basis for the synergistic regulation of the minimal TCR $\alpha$ enhancer by multiple proteins. We find that reconstitution of TCR $\alpha$ enhancer function in nonlymphoid cells requires expression of the lymphoid-specific proteins LEF-1, Ets-1 and PEBP2 $\alpha$ (CBF $\alpha)$, and a specific arrangement of their binding sites in the enhancer. We show that Ets-1 cooperates with PEBP2 $\alpha$ to bind adjacent sites at one end of the enhancer, forming a ternary complex that is unstable by itself. Stable occupancy of the Ets-1- and PEBP2 $\alpha$-binding sites in a DNase I protection assay was found to depend on both a specific helical phasing relationship with a nonadjacent ATF/CREB-binding site at the other end of the enhancer and on LEF-1. The HMG domain of LEF-1 was found previously to bend the DNA helix in the center of the TCR $\alpha$ enhancer. We now show that the HMG domain of the distantly related SRY protein, which also bends DNA, can partially replace LEF-1 in stimulating enhancer function in transfection assays. Taken together with the observation that Ets-1 and members of the ATF/CREB family have the potential to associate in vitro, these data suggest that LEF-1 can coordinate the assembly of a specific higher-order enhancer complex by facilitating interactions between proteins bound at nonadjacent sites.

[Key Words: LEF-1; PEBP2 $\alpha$; Ets-1; TCR $\alpha$ enhancer; DNA bending]

Received December 19, 1994; revised version accepted March 13, 1995.

DNA transactions, including transcription, recombination, and replication, involve the assembly of specific multiprotein complexes at cis-acting control regions (Echols 1986). The fidelity of assembly of such complexes, however, is challenged by the existence of protein families that are comprised of multiple members with virtually identical DNA-binding specificities and by large genomes that can sequester DNA-binding proteins nonspecifically. Therefore, recruitment of specific proteins to their genetic target sites in vivo has been proposed to require interactions between multiple DNAbinding proteins (Lin and Riggs 1975; Ptashne 1986). Together with the composition of cis-acting control regions as arrays of multiple factor-binding sites, such interactions may contribute to the accurate and diverse regulation of DNA transactions that occurs in prokaryotes and eukaryotes. One form of protein-protein interaction involves the dimerization of related or identical DNAbinding proteins that increases the affinity and specificity of sequence recognition (for review, see Johnson and McKnight 1989|. Moreover, the juxtaposition of binding

IPresent address: Chiron Corporation, Emeryville, CA 94608-2916. sites for different proteins that interact with each other can mediate cooperative DNA binding (Herskowitz 1990). Finally, contacts between proteins bound at nonadjacent sites involve looping or bending of the intervening DNA and allow for the generation of a higher-order nucleoprotein complex (for review, see Schleif 1992).

Assembly of higher-order nucleoprotein complexes has been studied extensively in site-specific recombination and transcription in prokaryotes. The formation of such complexes was shown to depend on "architectural" proteins that bend the DNA helix to facilitate the spatial alignment of nonadjacent factor-binding sites /for review, see Hoover et al. 1990; Nash 1990). In this context, protein-induced DNA bending is thought to overcome the energetic barrier for the deformation of short and inflexible DNA fragments (Shore and Baldwin 1983; Wang and Giaever 1988). Recently, several regulatory proteins, including the lymphocyte enhancer-binding factor 1 (LEF-1), the high mobility group (HMG) I/Y) protein, and the protein YY1 have been identified as putative structural components of protein complexes formed at eukaryotic enhancers and promoters /Giese et al. 1992; Thanos and Maniatis 1992; Du et al. 1993; Natesan and Gilman 1993|. 
LEF-1 is a pre-B and T lymphocyte-specific DNA-binding protein that is a member of the HMG domain family (Travis et al. 1991; Waterman et al. 1991). These proteins share an 85-amino-acid-region, termed the HMG domain, which recognizes DNA through the minor groove and induces a sharp bend in the DNA helix (for review, see Landsman and Bustin 1993; Grosschedl et al. 1994). In particular, LEF-1 induces a bend of $130^{\circ} \mathrm{C}$ in the double helix and can functionally replace the bacterial integration host factor (IHF), in the assembly of an higherorder nucleoprotein structure involved in site-specific recombination (Giese et al. 1992). LEF-1 cannot activate transcription by itself but must act in concert with other enhancer-bound proteins (Travis et al. 1991). In addition, LEF-1 contains an unique transcriptional activation domain that, when fused to a heterologous DNA-binding domain, maintains a dependence on a specific arrangement of flanking factor-binding sites for transcriptional stimulation (Carlson et al. 1993; Giese and Grosschedl 1993). One interpretation of this finding is that the transcriptional activation domain of LEF-1 mediates interaction between enhancer-bound transcription factors and, therefore, differs from typical activation domains that interact directly or indirectly with components of the basal transcription machinery (Lin and Green 1991; Hoey et al. 1993).

Studies of enhancer function have been facilitated by the observation that multimerization of individual factor-binding sites yields synthetic enhancers that often mimic the activity of natural enhancers (Herr and Clarke 1986). This seems to imply that the arrangement of individual factor-binding sites within natural enhancers is of relatively little importance. Recent data, however, suggest that the position and arrangement of factor-binding sites are important for function of certain natural enhancers and for the synergistic activation of transcription by enhancer-bound proteins (for review, see Tjian and Maniatis 1994). For example, multimerization of various factor-binding sites from enhancers does not allow for transcriptional activation, and the spacing of nonadjacent factor-binding sites can be important for enhancer function. Moveover, the specificity of the biological response of enhancer function can differ in natural and synthetic enhancers (Thanos and Maniatis 1992; Du et al. 19931.

One example of a natural enhancer that depends on a particular arrangement of factor-binding sites is provided by the minimal $\mathrm{T}$ cell receptor (TCR) $\alpha$-gene enhancer, which functions specifically in T lymphocytes. This enhancer contains a binding site for LEF- 1 in the center, and binding sites for the lymphocyte-specific protein Ets-1 and for a cell type-nonspecific protein of the activating transcription factor/cAMP response elementbinding (ATF/CREB) family at either end of the enhancer (Ho and Leiden 1990). Changes in the spacing between the ATF/CREB- and the LEF-1-binding sites impaired the activity of this enhancer (Ho and Leiden 1990). Moreover, multimerization of the LEF-1-binding site alone or in combination with the Ets-1-binding site did not generate an active enhancer complex (Waterman and Jones
1990; Travis et al. 1991). Together with the capacity of LEF- 1 to induce a sharp bend in the DNA helix, these data were interpreted to suggest a model in which LEF-1 serves as an architectural component in the assembly of a higher-order TCR $\alpha$ enhancer complex by facilitating interactions between ATF/CREB factors and Ets-1 (Giese et al. 1992). Here, we used biochemical and transfection assays to study the assembly and function of a specific multiprotein complex at the TCR $\alpha$ enhancer. We identified an additional $\mathrm{T}$ cell-specific protein, termed PEBP2 $\alpha$ (Ogawa et al. 1993a), that participates in the regulation of the TCR $\alpha$ enhancer. We provide evidence that LEF-induced DNA bending and interactions between proteins bound at adjacent and nonadjacent sites increase the specificity and stability of a higherorder nucleoprotein complex that forms at the TCR $\alpha$ enhancer.

\section{Results}

The T cell-specific protein PEBP2 $\alpha$ recruits Ets -1 into a ternary complex at the TCR $\alpha$ enhancer

Several lines of evidence suggest that in addition to ATF/ CREB, LEF-1, and Ets-1, other factors may participate in the regulation of the TCR $\alpha$ enhancer. First, transfection of LEF-1 and Ets-1 expression plasmids into HeLa cells conferred only modest activity on a cotransfected TCR $\alpha$ enhancer construct (data not shown). Second, DNase I footprint analysis of the TCR $\alpha$ enhancer with T cell nuclear extracts indicated that a region between the LEF-1and Ets-1-binding sites was protected from nuclease digestion (Ho et al. 1989; Winoto and Baltimore 1989). Finally, mutations in this region decreased the activity of the enhancer (data not shown). Inspection of the nucleotide sequence between the LEF-1- and Ets-1-binding sites identified two putative recognition motifs for a $\mathrm{T}$ cell-specific factor, termed core-binding factor (CBF; Wang et al. 1993) or polyoma enhancer-binding factor 2 (PEBP2; Ogawa et al. 1993a). This factor was shown to consist of a T cell-specific $\alpha$ subunit that mediates specific DNA recognition and a ubiquitously expressed $\beta$ subunit that modestly enhances DNA binding by the $\alpha$ subunit, apparently without contacting DNA (Ogawa et al. 1993a, b; Wang et al. 1993).

We examined binding of purified recombinant PEBP $2 \alpha$ protein to a radiolabeled DNA probe containing nucleotides $60-105$ of the minimal TCR $\alpha$ enhancer in an electrophoretic mobility-shift assay (EMSA) (Fig. 1A,B). PEBP2 $\alpha$ formed a specific complex that could be abrogated by mutations in either of the putative PEBP $2 \alpha-$ binding sites. The specificity of DNA recognition was confirmed by the resistance of the complex to competition with nonspecific DNA (data not shown). One of the PEBP2 $\alpha$-binding sites overlaps with the Ets-1 recognition sequence. Although binding of recombinant Ets-1 to the TCR $\alpha$ enhancer has been reported (Ho et al. 1990), this protein binds only weakly (Fig. 1C, lane 4). To examine whether PEBP $2 \alpha$ facilitates DNA binding by Ets-1, we incubated the 45-bp TCR $\alpha$ wild-type probe with purified 


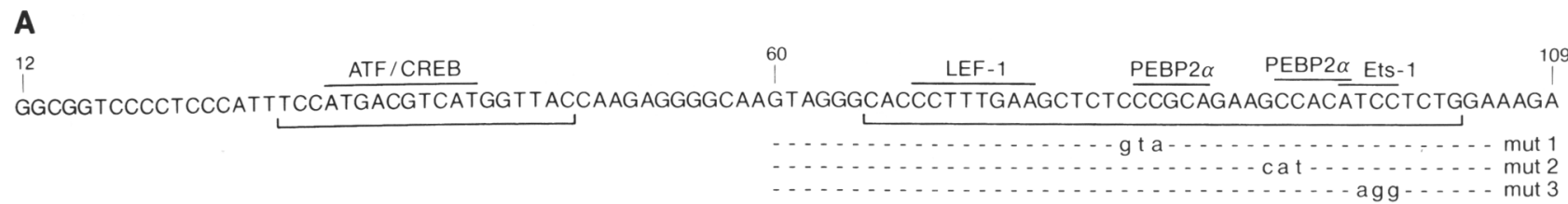

B

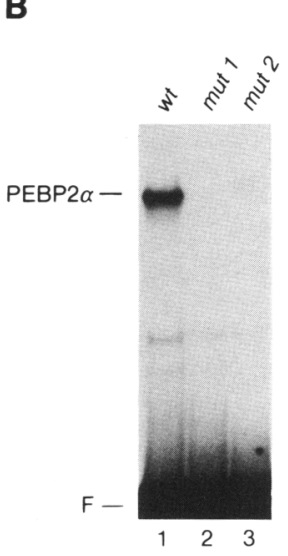

C

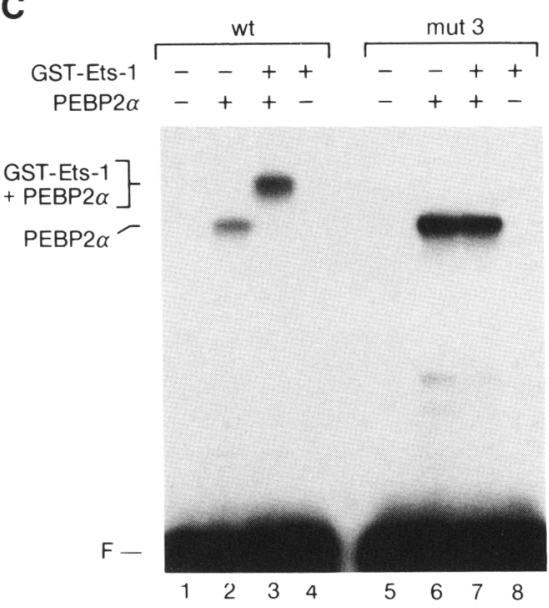

D GST-Ets-HA --+++
PEBP2 $\alpha-++++$
Antibody $-\quad-$ HA Myc

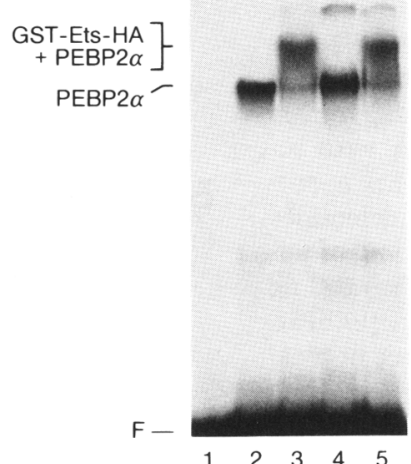

$\mathbf{E}$

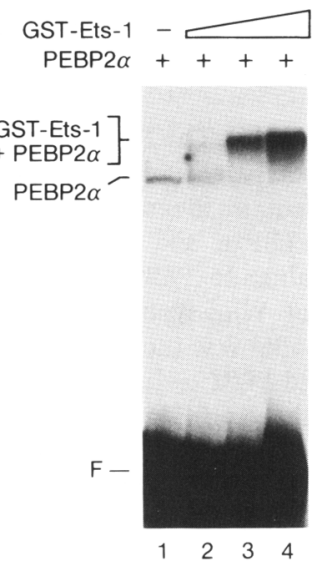

Figure 1. PEBP2 $\alpha$ and Ets-1 form a ternary complex at the TCR $\alpha$ enhancer. $(A)$ Nucleotide sequence of the 98-bp minimal human TCR $\alpha$ enhancer (position 12-109) with factor-binding sites indicated. The brackets below indicate the nucleotide sequences protected from DNase I digestion in T-cell nuclear extract (this study; Ho and Leiden 1989). Mutations in the PEBP2 $\alpha$-and Ets-1-binding sites are indicated with lowercase letters. $(B)$ EMSA of ${ }^{32} \mathrm{P}$-labeled wild-type TCR $\alpha$ oligonucleotide probes comprising nucleotide sequences 60-105 with $200 \mathrm{ng}$ of purified recombinant PEBP2 $\alpha$ protein. (Lane 1) Wild-type TCR $\alpha$ probe; (lanes 2,3) mutant TCR $\alpha$ probes containing nucleotide substitutions in the PEBP2 $\alpha$-binding sites. (C) EMSA of $200 \mathrm{ng}$ of purified PEBP2 $\alpha$ protein or 150 ng of purified GST-Ets-1 protein, or combined, with a TCR $\alpha$ wild-type probe (lanes 1-4) or a mutant probe (mut 3) containing base-pair substitutions in the Ets-1-binding site (lanes 5-8). Incubation of $\leqslant 2 \mu \mathrm{g}$ of GST-Ets-1 protein did not result in detectable DNA-binding activity (data not shown). (D) EMSA of PEBP2 $\alpha$ and GST-Ets-HA in the absence or presence of antibody against the HA epitope (lanes 2-4) or control antibody against a Myc epitope (lane 5). (E) EMSA of the TCR $\alpha$ wild-type probe with a constant amount of PEBP2 $\alpha$ (20 ng) and increasing amounts of GST-Ets-1 protein (lanes 2-4; $45 \mathrm{ng}, 150 \mathrm{ng}, 450 \mathrm{ng}$ ). The positions of the protein-DNA complexes and the free probes $(\mathrm{F})$ in each experiment are indicated.

glutathione $S$-transferase (GST)-Ets-1 protein alone or in combination with recombinant PEBP $2 \alpha$ (Fig. 1C). Coincubation of PEBP2 $\alpha$ and GST-Ets-1 yielded a complex that migrated with a slower mobility than that formed with PEBP2 $\alpha$ alone (lanes 2,3). No detectable complex was formed with GST-Ets-1 protein alone (lane 4) suggesting that PEBP2 $\alpha$ augments DNA binding by GSTEts-1.

To determine whether the formation of the slower migrating complex is dependent on the Ets-binding site, we mutated the trinucleotide 5'-GGA, which was shown previously to constitute the core motif for members of the Ets-family of DNA-binding proteins (Karim et al. 1990). Formation of the slower migrating complex with this mutated DNA probe (mut 3) was abrogated, whereas PEBP2 $\alpha$ binding was observed at normal levels (Fig. 1C, lanes 6,71 . To confirm the presence of GST-Ets-1 in the slower migrating complex, we performed a gel mobilityshift assay with a hemagglutinin (HA)-tagged GST-Ets-1 protein. Addition of monoclonal antibody against the HA epitope abrogated the formation of the slower migrating complex but did not affect DNA binding by PEBP2 $\alpha$ (Fig. 1D, lanes 3,4). No change in the mobility of the slower migrating ternary complex was observed with control antibody (lane 5). On the basis of the inability of GST-Ets- 1 to bind TCR $\alpha$ DNA by itself, we examined whether this protein can bind DNA cooperatively with PEBP2 $\alpha$. To this end, we used a constant but limiting amount of PEBP $2 \alpha$ protein and increased the concentration of GST-Ets-1 protein in the EMSA. The abundance of the ternary complex increased 20 -fold at the maximal concentration of added GST-Ets-1 protein (Fig. 1E). Together, these data suggest that DNA binding by PEBP $2 \alpha$ and GST-Ets-1 is highly cooperative.

PEBP $2 \alpha$ protein is a member of the "Runt family" of proteins (Kagoshima et al. 1993). To examine whether the DNA-binding domain of PEBP2 $\alpha$, termed the Runt domain, is sufficient to form a ternary complex with Ets-1, we incubated the 45-bp TCR $\alpha$ probe with purified Runt domain alone or together with GST-Ets-1 (Fig. 2). Addition of GST-Ets-1 protein decreased the rate of migration of the Runt domain-DNA complex and increased its abundance (Fig. 2B, lanes 4,5). This suggests that Ets-1 can cooperate with the Runt domain of PEBP $2 \alpha$ to bind DNA.

The capacity of the Runt domain to recruit GST-Ets-1 
Figure 2. The Runt domain of PEBP2 $\alpha$ interacts with a defined region of Ets-1. $(A)$ Schematic diagrams of deletion derivatives of PEBP $2 \alpha$ and Ets-1. (B) EMSA with recombinant PEBP $2 \alpha$ and GST-Ets-1 proteins. Wild-type TCR $\alpha$ probe (nucleotides 60-105) was incubated with $200 \mathrm{ng}$ of purified PEBP2 $\alpha$ (lanes 2,3 ) or with $\sim 200 \mathrm{ng}$ of the Runt domain of PEBP $2 \alpha$ [PEBP $2 \alpha$ (93-226)] (lanes 4,5) in the absence or presence of $150 \mathrm{ng}$ of GST-Ets-l protein. (Lane 6) Binding reaction with $150 \mathrm{ng}$ of GSTEts-1. (C) In vitro association assay between GST-Runt domain immobilized on glutathione agarose beads and in vitro ${ }^{35} \mathrm{~S}$ labeled Ets-1 polypeptides. (Top) Ten percent of radiolabeled full-length and truncated Ets-1 polypeptides. Molecular size markers are shown in kilodaltons. (Middle) In vitro association of Ets-1 proteins with GST-Runt domain. (Bottom) In vitro association of Ets-1 proteins with GST protein. The input and the bound proteins were analyzed by SDS-PAGE and visualized by autoradiography.

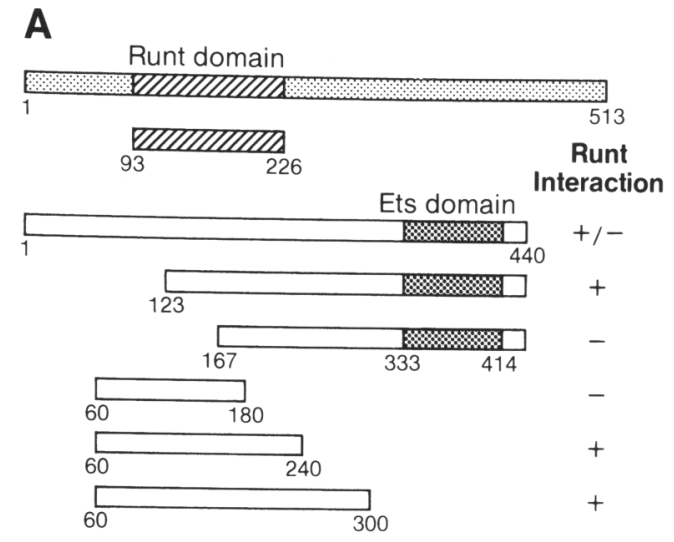

B

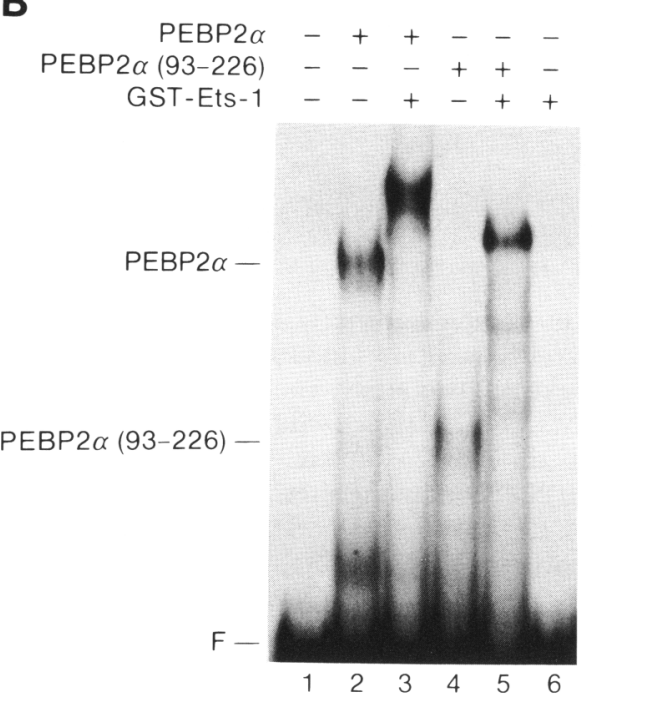

into a ternary complex suggested that these proteins may interact directly with each other. To this end, we examined whether ${ }^{35} \mathrm{~S}$-labeled wild-type or truncated Ets-1 polypeptides can interact with immobilized GST-Runt domain fusion protein (Fig. 2C). We included ethidium bromide in this experiment to disrupt nonspecific interactions caused by contaminating DNA (Lai and Herr 1992). Weak association was observed with full-length Ets-1 protein (lane 1). Significant association was observed with the truncated Ets-1 polypeptides $\mathrm{N} \Delta 123,60$ / 300 , and $60 / 240$ (lanes $2,4,5$ ). This association seems to be specific, as no interaction was observed between ${ }^{35} \mathrm{~S}$ labeled Ets-1 polypeptides and immobilized GST protein. The lack of association between immobilized GSTRunt domain and N $\Delta 167$ Ets-1 and 60/180 (lanes 3,6) delineates the interaction domain in Ets-1 to between amino acids 123 and 240.

Synergistic function of factor-binding sites in the TCR $\alpha$ enhancer

To determine the functional role of PEBP $2 \alpha$ and the other TCR $\alpha$ enhancer-binding proteins in vivo, we mutated individual factor-binding sites in the context of the minimal enhancer. Transfections of the wild-type TCR $\alpha$ enhancer into $T$ cells increased the activity of a linked minimal fos promoter 55 -fold (Fig. 3A). Mutations in one of the PEBP $2 \alpha$-binding sites (TCR $\alpha \mathrm{M} 3$ ) decreased enhancer function by a factor of 10 . Likewise, mutations in any of the binding sites for Ets-1 (TCR $\alpha$ M4), ATF/CREB (TCR $\alpha \mathrm{M} 1$ ), and LEF-1 (TCR $\alpha \mathrm{M} 2$ ) resulted in a similar 9- to 16-fold reduction in TCR $\alpha$ enhancer function, suggesting that proteins recognizing these four binding sites synergize to activate transcription.

This synergy could reflect interactions between multiple enhancer-bound proteins. To examine whether a specific helical phasing relationship is necessary for TCR $\alpha$ enhancer function, we inserted 4 nucleotides between the ATF/CREB- and LEF-1-binding sites. This mutation (TCR $\alpha+4)$ decreased the activity of the TCR $\alpha$ enhancer in $T$ cells by a factor of three (Fig. 3B). In contrast, insertion of 10 nucleotides (TCR $\alpha+10$ ), which maintained the helical phasing relationship, did not alter the activity of the enhancer. These data suggest that an ATF/CREB protein interacts functionally with a factor bound at one of the downstream sites. To further explore the requirement for a specific arrangement of factorbinding sites in the TCR $\alpha$ enhancer, we generated two 
A
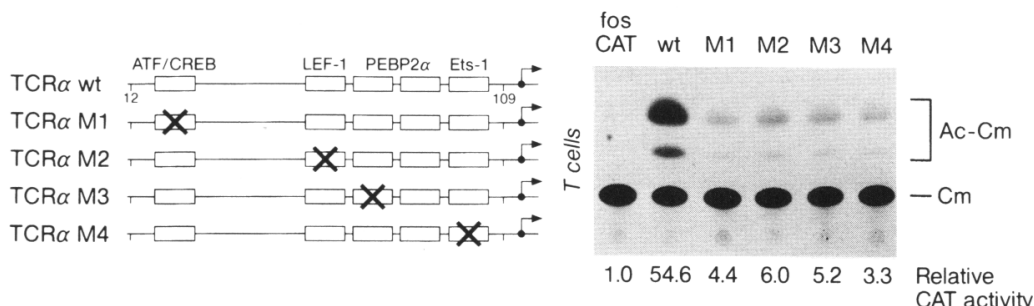

B
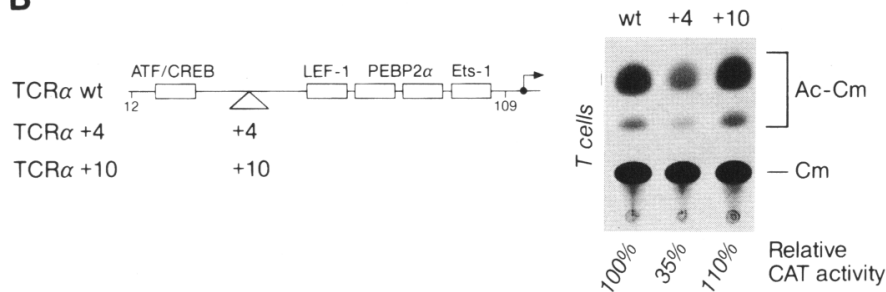

C

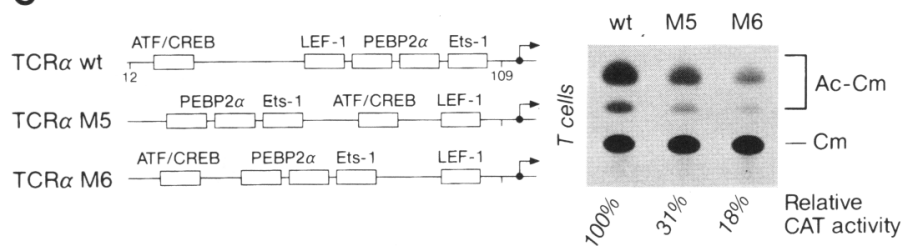

Figure 3. Synergistic function of factor-binding sites in the TCR $\alpha$ enhancer. $(A)$ Schematic diagram of wild-type and mutant TCR $\alpha$ enhancer constructs containing nucleotide substitutions in the ATF/CREB-, LEF-1-, PEBP2 $\alpha$-, or Ets-1-binding sites. In these constructs the TCR $\alpha$ enhancer was linked to the minimal fos promoter $1-56$ to $+109)(0)$, and the chloramphenicol acetyltransferase (CAT) gene. BW5147 T cells were transfected with $1 \mu \mathrm{g}$ of the TCR $\alpha$ enhancer constructs shown in $A$. CAT levels shown are relative to the level obtained with a fos/CAT reporter construct lacking an insert. $(B)$ Schematic diagram of wildtype and mutant TCR $\alpha$ enhancer constructs with 4 or 10 nucleotides inserted between the ATF/ CREB- and LEF-1-binding sites. T cells were transfected with $1 \mu \mathrm{g}$ of the different TCR $\alpha$ reporter constructs. $(C)$ TCR $\alpha$ enhancer constructs with altered spatial arrangement of factor-binding sites. $\mathrm{T}$ cells were transfected with $1 \mu \mathrm{g}$ of the different TCR $\alpha$ reporter constructs. Two hundred nanograms of a pRSV-luciferase plasmid was included in all transfection experiments as an internal standard. CAT activities were determined relative to $100 \%$ wild-type activity. Representative CAT assays from a minimum of three experiments are shown. The variability between individual experiments was $<15 \%$. mutations in which the LEF-1-binding site was placed at the $3^{\prime}$ end of the enhancer. Transfection of these mutant enhancer constructs in which the ATF/CREB-binding site was juxtaposed with the binding sites for either Ets-1 (TCR $\alpha$ M5) or PEBP2 $\alpha$ (TCR $\alpha$ M6) showed a threefold and sixfold decrease in enhancer function, respectively (Fig. 3C). Mutation of the LEF-1-binding site in the TCR $\alpha$ M 5 construct did not decrease enhancer activity further (data not shown), indicating that LEF-1 is unable to function in an altered context of factor-binding sites. Together, these observations suggest the importance of a specific arrangement of factor-binding sites in the TCR $\alpha$ enhancer.

\section{Reconstitution of TCR $\alpha$ enhancer function in nonlymphoid cells}

Previously, we and others have found that LEF-1 stimulates TCR $\alpha$ enhancer function in B cells that contain Ets-1 but lack LEF-1 and PEBP2 $\alpha$ (Travis et al. 1991; Carlson et al. 1993; Giese and Grosschedl 1993). To examine whether the activity of the TCR $\alpha$ enhancer could be increased further by expression of PEBP $2 \alpha$, we transfected into B cells a wild-type TCR $\alpha$ reporter construct together with expression plasmids for LEF-1 or PEBP $2 \alpha$, or both (Fig. 4A). A 15-fold stimulation of enhancer activity was observed with LEF-1 and PEBP $2 \alpha$, a level sig- nificantly higher than the multiplicative product of the levels observed with LEF-1 and PEBP2 $\alpha$ alone (Fig. 4A). With the aim of reconstituting TCR $\alpha$ enhancer function in nonlymphoid cells, we transfected into HeLa cells a $\mathrm{TCR} \alpha$ reporter gene construct together with various combinations of expression plasmids for LEF-1, PEBP $2 \alpha$, and Ets-1 (Fig. 4B). Individual expression of any of these proteins did not increase the basal activity of the reporter construct significantly. Pairwise transfections of these expression plasmids indicated that Ets- 1 in combination with either LEF-1 or PEBP2 $\alpha$ increased enhancer function seven- to eightfold. Coexpression of all three proteins stimulated TCR $\alpha$ enhancer activity 36 -fold to a level similar to that observed in T cells.

The presence of multiple Ets family members in lymphoid cells raises questions as to the recruitment of one particular member to the TCR $\alpha$ enhancer. In particular, Ets-1 and Fli-1 are both expressed in T and B cells and have very similar DNA-binding specificities (Wang et al. 1992; Gunther and Graves 1994). Moreover, purified recombinant Fli-1 protein resembles Ets- 1 in its inability to bind the TCR $\alpha$ enhancer by itself and in its ability to cooperate with PEBP $2 \alpha$ to form a ternary complex in EMSAs (data not shown). To examine whether Fli-1 can participate in the stimulation of TCR $\alpha$ enhancer activity in HeLa cells, we cotransfected expression plasmids for Fli-1, LEF-1, and PEBP2 $\alpha$, together with a TCR $\alpha$ reporter construct (Fig. 4C). In comparison with Ets-1, Fli-1 showed a significantly reduced ability to stimulate 
A

Figure 4. Reconstitution of TCR $\alpha$ enhancer activity in $\mathrm{B}$ cells and nonlymphoid cells. $(A)$ Namalwa B cells were transfected with $1 \mu \mathrm{g}$ of expression plasmids for LEF-1 and PEBP $2 \alpha$ individually or together with $0.5 \mu \mathrm{g}$ of a wild-type TCR $\alpha$ enhancer construct. $(B)$ HeLa cells were transfected with $1 \mu \mathrm{g}$ of expression plasmids for LEF-1, PEBP2 $\alpha$, or Ets-1 alone or in various combinations together with $0.3 \mu \mathrm{g}$ of a wildtype reporter plasmid. $(C) \mathrm{HeL}$ a cells were transfected as described above except that $1 \mu \mathrm{g}$ of expression plasmid for Fli-1 was added as indicated. Representative CAT assays are shown for each experiment. Two hundred nanograms of a pRSV-luciferase plasmid was included in all transfection experiments as an internal standard. CAT levels shown are relative to the level obtained with the reporter plasmid alone. The amount of DNA in each transfection experiment was kept constant by adding an LEF-1 expression plasmid containing a frameshift mutation in the insert. Represen. tative CAT assays from a minimum of three experiments are shown. The variability between individual experiments was $<20 \%$. (D) Expression levels of LEF-1, Ets-1, PEBP $2 \alpha$, and Fli-1. COS-7 cells were transfected with expression plasmids for HAtagged LEF-1, Ets-1, PEBP2 $\alpha$, and Fli-1. Nuclear extracts were prepared and proteins were separated by SDS-PAGE. The proteins were detected by immunoblot analysis using monoclonal antibodies directed against the HA epitope tag. Molecular size markers are shown in kilodaltons.

TCR $\alpha$ enhancer function in this context. Immunoblot analysis of lysates of COS cells transfected with expression plasmids encoding HA epitope-tagged proteins confirmed that Fli-1 was expressed in these cells at an even higher level than Ets-1 (Fig. 4D). Assuming that the levels of steady-state expression of Fli-l and Ets-1 are similar in COS and HeLa cells, these data suggest that specific members of the Ets family of proteins differ in their potential to synergize with other proteins to regulate the TCR $\alpha$ enhancer.

\section{LEF-induced DNA bending contributes \\ to the regulation of TCR $\alpha$ enhancer function}

The helical phasing experiment strongly suggested that an ATF/CREB protein interacts functionally with proteins bound at a nonadjacent site. Such an interaction would require the deformation of the intervening DNA helix. DNA binding by LEF-1 has been shown previously to induce a sharp bend in the DNA helix /Giese et al. 1992). To examine whether LEF-induced DNA bending contributes to TCR $\alpha$ enhancer function, we used the HMG domain of LEF-1 in trans-activation experiments. To this end, we transfected into HeLa cells the wild-type TCR $\alpha$ enhancer construct, together with expression plasmids encoding PEBP $2 \alpha$, Ets-1, and the HMG domain of LEF-1. The HMG domain of LEF-1 increased the activity of the enhancer two- to threefold relative to the level observed with PEBP2 $\alpha$ and Ets-1 alone (Fig. 5A).
B

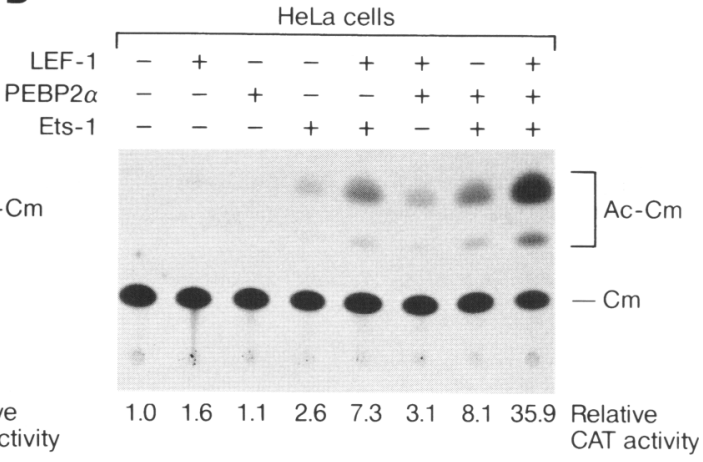

C

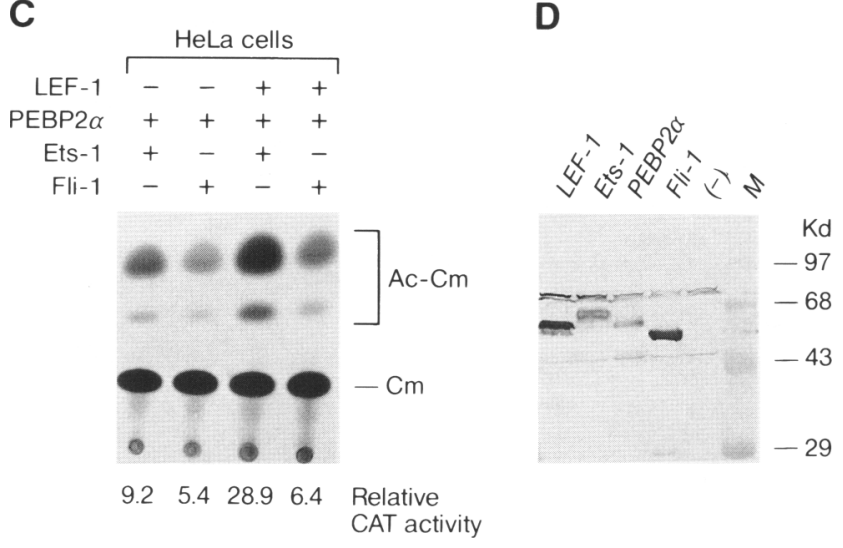

This stimulation of $\mathrm{TCR} \alpha$ enhancer function by the LEF-HMG domain was two times less efficient than that obtained with intact LEF-1 in a parallel experiment (data not shown). To obtain further support for a role of protein-induced DNA bending rather than protein-protein interaction, we used the HMG domain of the distantly related testis-determining factor SRY in a transfection experiment. The HMG domains of LEF-1 and SRY both bend the DNA helix but share only $24 \%$ amino acid identity (Ferrari et al. 1992; Giese et al. 1992, 1994). The SRY-HMG domain also increased, by a factor of two to three, the activity of a TCR $\alpha$ enhancer in which the LEFl-binding site had been replaced with the SRY-binding site (Fig. 5B). In contrast, the activity of a TCR $\alpha$ enhancer containing a LexA-binding site, instead of the LEF-1-binding site, cannot be increased by LexA in transfection assays (Giese and Grosschedl 1993). Together with the analysis of mutations in the TCR $\alpha$ enhancer, these data support a role for DNA bending in the regulation of the TCR $\alpha$ enhancer.

\section{Association between Ets-1 and members of the ATF/CREB family}

The ATF/CREB-binding site in the TCR $\alpha$ enhancer strongly resembles a cAMP response element, although the enhancer is not responsive to CAMP (Waterman and Jones 1990). A virtually identical sequence motif in the $T$ 


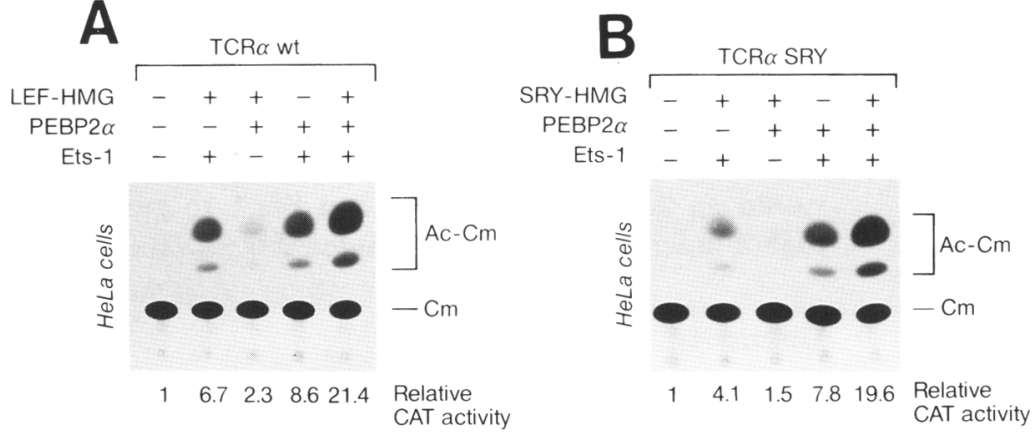

Figure 5. HMG domain-induced DNA bending participates in the regulation of TCR $\alpha$ enhancer activity. $(A)$ Trans-activation of a TCR $\alpha$ enhancer reporter construct by the HMG domain of LEF-1. HeLa cells were transfected with $1 \mu \mathrm{g}$ of expression plasmids for the HMG domain of LEF-1, PEBP $2 \alpha$, and Ets- 1 in various combinations together with $0.3 \mu \mathrm{g}$ of a wild-type TCR $\alpha$ enhancer reporter plasmid. (B) Trans-activation of a modified TCR $\alpha$ enhancer construct, in which the LEFl-binding site had been replaced with the SRYbinding site, by the HMG domain of the testisdetermining factor SRY. HeLa cells were transfected with $1 \mu \mathrm{g}$ of expression plasmids for the SRY-HMG domain, PEBP2 $\alpha$, and Ets-1 in different combinations together with $0.3 \mu \mathrm{g}$ of the modified TCR $\alpha$ enhancer construct. Two hundred nanograms of a pRSV-luciferase plasmid was included in all transfection experiments as an internal standard. The variability between individual experiments was $<10 \%$. Representative CAT assays from multiple transfections are shown for each experiment.

cell-specific CD3 $\delta$ enhancer was shown previously to be recognized in thymocytes by various isoforms of the CRE-binding protein (CRE-BP) (Georgopoulos et al. 1992), which is identical to ATF-2 (Maekawa et al. 1989; Hai et al. 1990). In EMSAs, the ATF/CREB-binding site in the TCR $\alpha$ enhancer can be recognized by recombinant CREB and ATF- 2 proteins and by proteins in T cells that react with monoclonal antibodies directed against ATF1, ATF-2, and CREB (C. Kingsley and R. Grosschedl, unpubl.). To examine whether either CREB or ATF-2 can interact directly with one of the three proteins that recognize the $3^{\prime}$ half of the TCR $\alpha$ enhancer, we performed a protein affinity blot analysis. In this assay, total bacterial lysates containing various $\mathrm{TCR} \alpha$ enhancer-binding proteins were immobilized on a nitrocellulose membrane and incubated with ${ }^{35} \mathrm{~S}$-labeled Ets-1 polypeptide in the presence of ethidium bromide (Fig. 6A,B). In preliminary experiments we detected weak associations of Ets-l with both CREB and the ATF-2 195 isoform, which is the predominant activating form of ATF-2 (Du and Maniatis 1994), but not with other TCR $\alpha$ enhancer-binding proteins (data not shown). Significant association, however, was detected between Ets-1 and the ATF-2 ${ }_{194}$ isoform, which lacks part of the dimerization domain (see Materials and methods). The interaction between Ets-1 and ATF- $2_{194}$ was also detected in an association assay in which nondenatured GST-ATF- $2_{194}$ protein was immobilized on agarose beads (Fig. 6C). This association was dependent on an amino-terminal region in Ets-l and the presumably monomeric nature of GST-ATF-2 ${ }_{194}$, because no significant association was detected between Ets- 1 and GST-ATF- $2_{195}$ or CREB in this assay.

\section{$L E F-1$ and an ATF/CREB protein collaborate} in the stabilization of DNA binding by PEBP $2 \alpha$ and Ets-1

The contribution of DNA bending to TCR $\alpha$ enhancer function and the potential of ATF/CREB proteins to associate with Ets-1 raised the interesting possibility that LEF-1 facilitates the assembly of a higher-order nucleoprotein complex by juxtaposing the widely separated
ATF/CREB- and Ets-1-binding sites. Although PEBP $2 \alpha$ and Ets-l cooperate to bind the TCR $\alpha$ enhancer, the ternary complex is very unstable. Determination of the resistance of the PEBP2 $\alpha$-Ets-1-DNA complex to excess unlabeled TCR $\alpha$ probe in EMSAs as a function of time indicated a half-life of $<5 \mathrm{sec}$ for the complex at $20^{\circ} \mathrm{C}$ (data not shown). Consistent with the short half-life of this complex, purified PEBP2 $\alpha$ and Ets-1 were unable to protect their binding sites in a DNase I footprint assay even with PEBP $2 \beta$ included in the reaction /data not shown). Attempts to examine the potential of bacterially expressed ATF- 2 and LEF-1 to augment DNA binding by PEBP2 $\alpha$ and Ets- 1 failed, possibly because of a requirement for a different member of the ATF/CREB family, post-translational modification of the protein, or association with an additional yet unidentified cofactor.

Therefore, we performed DNase I protection assays with nuclear extracts from HeLa cells complemented with various combinations of purified lymphocyte-specific proteins. Incubation of a radiolabeled TCR $\alpha$ probe with nuclear extract from HeLa cells that had been infected with a recombinant LEF-1-vaccinia virus resulted in protection of the ATF/CREB- and LEF-1-binding sites (Fig. 7A, lanes 2-6). Addition of a constant amount of GST-Ets- 1 and increasing amounts of PEBP2 $\alpha$ proteins generated a DNase I footprint that included both the PEBP $2 \alpha$ - and Ets-1-binding sites (lanes 5,6 ). The extent of this footprint was similar to that observed previously with T cell nuclear extract (Ho et al. 1989; Winoto and Baltimore 1989). To examine the LEF-1 dependence of this DNase I footprint, we used an extract from HeLa cells infected with a HA-vaccinia virus (lanes 10-13). In this extract, addition of purified PEBP2 $\alpha$ and GST-Ets- 1 did not result in a footprint suggesting that LEF-1 is essential for the stabilization of the PEBP $2 \alpha-E$ ts- 1 complex (lane 11). Indeed, addition of either purified LEF-1 or the HMG domain of LEF-1 generated a DNase I footprint at the PEBP2 $\alpha$ - and Ets-1-binding sites (lanes 12,13).

ATF/CREB proteins can associate with Ets- 1 in the absence of DNA and the function of the TCR $\alpha$ enhancer requires a particular helical phase between the ATF/ CREB- and the downstream factor-binding sites. To- 

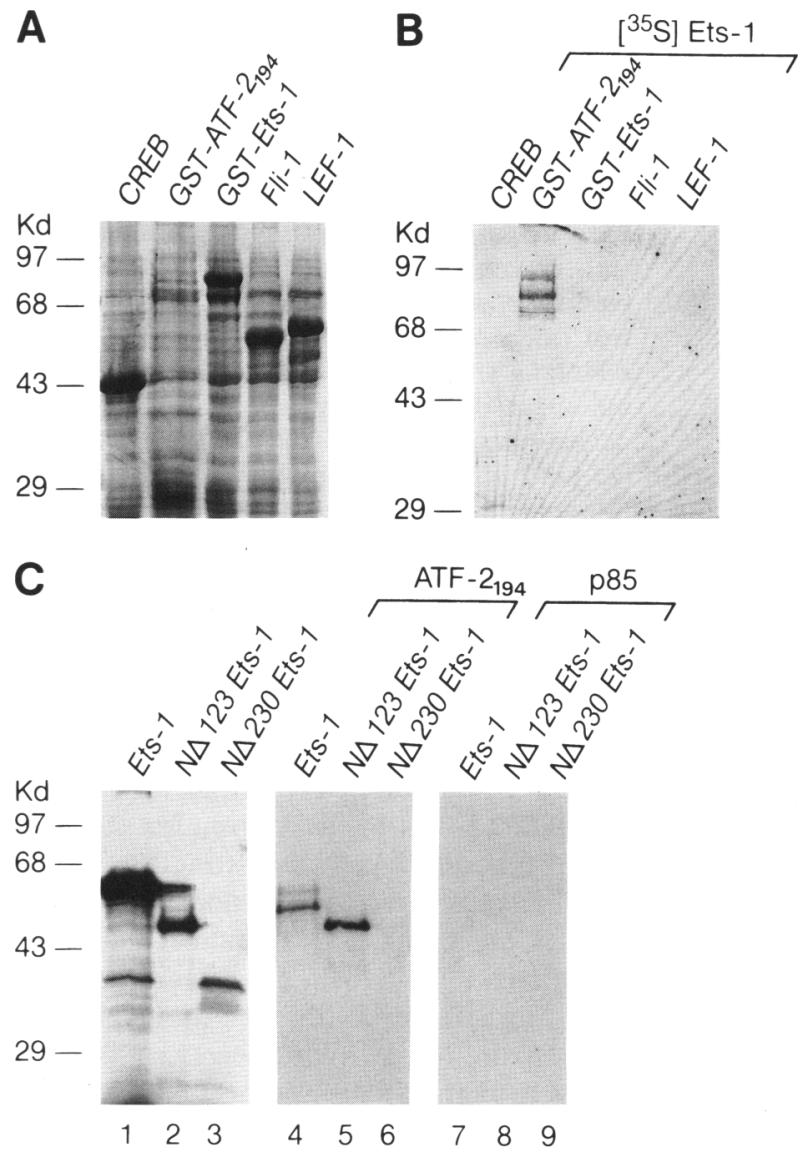

Figure 6. Association between ATF- $2_{194}$ and Ets-1. (A) TCR $\alpha$ enhancer-binding proteins were expressed in Escherichia coli and total lysates were analyzed by SDS-PAGE. Proteins were visualized by Coomassie Blue staining, and in parallel transferred onto nitrocellulose membranes. Molecular size markers are shown in kilodaltons. $(B)$ The immobilized proteins were assayed for protein interaction by incubation of the nitrocellulose membrane with in vitro-translated ${ }^{35} \mathrm{~S}$-labeled Ets-1. The largest detected polypeptide corresponds to the expected molecular weight of the GST-ATF- $2_{194}$ fusion protein. The additional proteins may represent degradation products of the fusion protein. $(C)$ Association of Ets-1 with GST-ATF- ${ }_{194}$ immobilized on glutathione-agarose beads. (Lanes 1-3) 10\% input of radiolabeled full-length and truncated Ets-l polypeptides. In vitro associations of Ets-1 proteins with immobilized GST-ATF- $2_{194}$ protein (lanes 4-6) or immobilized GST-p85 protein (lanes 7-9). The input and the bound proteins were analyzed by SDS-PAGE and visualized by autoradiography.

gether these observations can be interpreted to suggest that an ATF/CREB protein also contributes to stabilization of DNA binding by PEBP $2 \alpha$ and Ets-1. To test this possibility, we performed the DNase I footprint analysis with the mutant TCR $\alpha+4$ enhancer in which 4 nucleotides had been inserted between the ATF/CREB- and LEF-1-binding sites (Fig. 7B). In contrast to the wild-type TCR $\alpha$ fragment, no footprint at the PEBP2 $\alpha$ - and Ets-1binding sites was observed despite the presence of LEF-1 (lanes 6,7). This result strongly suggests that the stabili- zation of the PEBP2 $\alpha$-Ets-1 complex at the TCR $\alpha$ enhancer is dependent on both the HMG domain of LEF-1 and a protein bound at the ATF/CREB-binding site. Taken together, these data support a model in which a LEF-induced DNA bend facilitates an interaction between an ATF/CREB protein and Ets-1 to generate a higher-order nucleoprotein complex (Fig. 8).

\section{Discussion}

In this report we provide evidence that various proteinprotein and protein-DNA interactions contribute to the coordinate assembly and synergistic function of multiple factors at the minimal TCR $\alpha$ enhancer: (1) Interactions between two sequence-specific proteins that bind adjacent sites in the enhancer mediate cooperative DNA binding; (2) interactions between proteins that bind nonadjacent sites in the enhancer stabilize DNA-bound proteins; and (3) protein-induced DNA bending facilitates the interaction between proteins bound at nonadjacent sites and contributes to the assembly of a higher-order nucleoprotein structure.

\section{Ternary complex formation of factors bound at adjacent sites}

In the TCR $\alpha$ enhancer, we observed cooperative DNA binding by the lymphocyte-specific proteins PEBP2 $\alpha$ and Ets-1 that recognize adjacent sites. Similar to the ternary complex formed at the c-fos promoter between the serum response factor (SRF) and the Ets proteins Elk-1 or SAP-1 (Dalton and Treisman 1992; Janknecht and Nordheim 1992; Hill et al. 1993), we found that binding of PEBP2 $\alpha$ and Ets- 1 to the TCR $\alpha$ enhancer is augmented $\sim 20$-fold. This cooperativity of DNA binding presumably involves protein-protein contacts between the Runt domain of PEBP2 $\alpha$ and Ets-1. Such interactions may antagonize an inhibitory domain between amino acids 207 and 280 of Ets-1 that was found previously to impair DNA binding by Ets-1 (Lim et al. 1992). Consistent with this view, removal of these amino acid residues allows Ets- 1 to bind the TCR $\alpha$ enhancer by itself, although the level of DNA binding could be increased further by interaction with PEBP2 $\alpha$ (data not shown). Moreover, the nucleotide sequence of the Ets-1-binding site may influence the relative dependence of Ets-1 on PEBP2 $\alpha$ for DNA recognition. For example, the TCR $\beta$ enhancer, which contains an arrangement of factor-binding sites similar to that in the TCR $\alpha$ enhancer but differs in the sequence of the Ets-1-binding site, is recognized by Ets-1 in the absence of partially purified CBF/PEBP protein (Wotton et al. 1994). The half-life of the ternary complex, however, is twofold longer than that of the Ets-1-DNA complex (Wotton et al. 1994).

In contrast to the stability of SRF- and SRF-Elk-1DNA complexes, which can be detected readily in DNase I protection assays, we found that the stability of the PEBP $2 \alpha-$ DNA complex and that of the PEBP2 $\alpha$-EtsDNA ternary complex appears to be low. The half-life of this ternary complex, as measured by competition of 
A

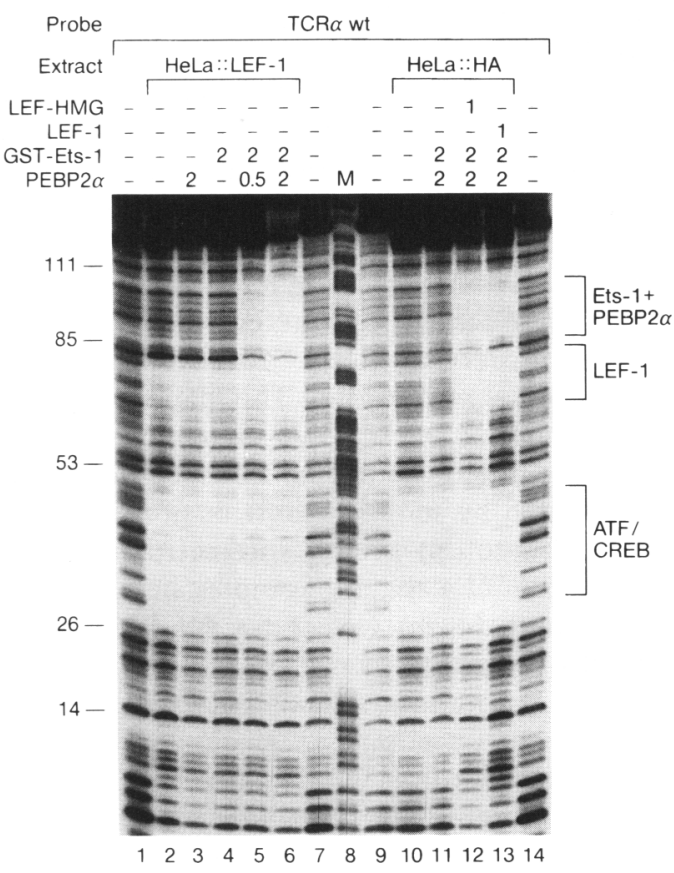

B

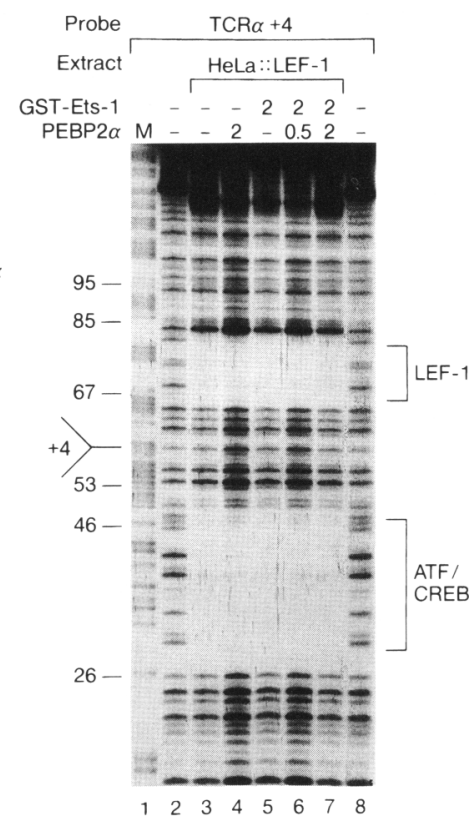

Figure 7. Stabilization of the PEBP2 $\alpha-$ Ets-1-DNA ternary complex by LEF-1 and an ATF/CREB protein. (A) DNase I footprint analysis of the $5^{\prime}$-endlabeled wildtype TCR $\alpha$ DNA fragment (12-109) using HeLa cell nuclear extract infected with a recombinant vaccinia vinus expressing either LEF-1 (lanes 1-7) or HA protein (lanes 9-14). Nuclear extracts were complemented with purified lymphocyte-specific proteins. The amount of each protein added is indicated at top (in $\mu \mathrm{g}$ ). Brackets indicate DNase I-protected regions. Lane $M$ contains a $G+A$ sequence ladder of the same DNA fragment. $(B)$ DNase I footprint analysis of the mutant TCR $\alpha+4$ DNA probe in HeLa cell nuclear extract infected with a vaccinia virus expressing LEF-1 protein. The position of the inserted nucleotides is indicated at left. binding in EMSAs, is very short $(<5 \mathrm{sec})$. Moreover, we did not observe protection of the PEBP2 $\alpha$ - and Ets-1binding sites in a DNase I footprint assay, even in the presence of PEBP2 $\beta$. Occupancy of these binding sites in DNase I protection assays was shown to require LEF-1 and a specifically positioned upstream ATF/CREB-binding site, suggesting that the PEBP2 $\alpha-E$ ts-1-DNA ternary complex is stabilized by interaction with other proteins (see below).

Consistent with the cooperative DNA binding by

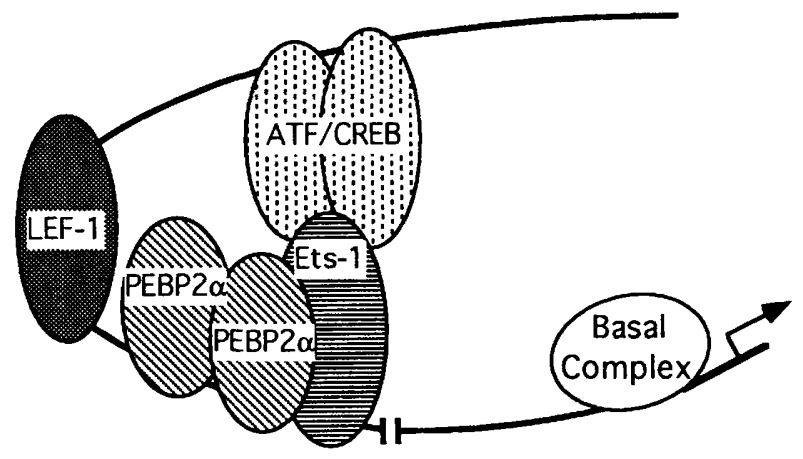

Figure 8. Model of the multiprotein complex formed at the minimal TCR $\alpha$ enhancer. The LEF-induced DNA bend at a specifically positioned site in the enhancer augments binding of a PEBP2 $\alpha$-Ets-1 complex through protein-protein interactions with an ATF/CREB protein, which results in the assembly of a higher-order nucleoprotein complex.
PEBP2 $\alpha$ and Ets-1, we observed synergy of activation of the TCR $\alpha$ enhancer by these proteins in transfection assays. A similar synergy was also observed between Ets-1 and LEF- 1 but not between PEBP2 $\alpha$ and LEF-1. Moreover, we found that Ets-1 could synergize with the HMG domains of either LEF-1 or SRY. This functional synergy may be indirect and involve the interaction between Ets-1 and an ATF/CREB protein, because we were unable to detect specific interactions between Ets-1 and the HMG domain of LEF-1 in vitro. One interpretation of this finding is that the HMG domain synergizes with Ets-1 by bending the DNA helix and juxtaposing the nonadjacent ATF/CREB- and Ets-1-binding sites.

\section{LEF-induced DNA bending in assembly and function of the TCR $\alpha$ enhancer complex}

We have shown previously by circular permutation analysis and by a prokaryotic site-specific recombination assay in vitro that LEF-1 induces a sharp bend in the DNA helix (Giese et al. 1992). However, it is difficult to distinguish whether protein-induced DNA bending has a functional role in regulating gene expression or whether it reflects a particular mode of sequence recognition. For example, LEF-1 and HMG-I/Y), along with other DNAbending proteins like IHF and TATA-binding protein (TBP) recognize the minor groove of the DNA helix (Yang and Nash 1989; Starr and Hawley 1991; Giese et al. 1992; Thanos and Maniatis 1992). Therefore, the distortion of the DNA helix induced with binding of these proteins could be necessary solely to widen the minor groove for optimal sequence recognition as detected in 
the TBP-DNA complex (J. Kim et al. 1993; Y. Kim et al. 1993). However, various observations support the view that DNA bending by LEF-1 contributes to normal function of the minimal TCR $\alpha$ enhancer.

The helical phasing relationship between the ATF/ CREB- and the LEF-1-binding sites in the TCR $\alpha$ enhancer was found to be important both for the assembly of a stable nucleoprotein complex in vitro and for enhancer function in transfection assays. The activity of the enhancer was decreased threefold by rotating the ATF/CREB-binding site half a helical turn relative to the LEF-1-binding site but was restored to wild-type levels by an additional half-helical rotation. A similar requirement for a specific helical phase between factor-binding sites was observed in the c-fos promoter in which changes in the relative positions of binding sites for CREB and YYl were shown to influence transcription by a factor of four to five (Natesan and Gilman 1993). In this context, YY1 is bound between the CREB site and the TATA box and is thought to juxtapose these nonadjacent sites by DNA bending. A structural role for YYl in organizing promoter topology was supported further by demonstrating that YYl in the c-fos promoter could be replaced functionally with a binding site for the HMG domain of SRY that bends the DNA helix (Natesan and Gilman 1993). Likewise, the HMG domain of SRY can partially replace LEF-1 in stimulating the TCR $\alpha$ enhancer activity in transfection assays. The HMG domains of LEF-1 and SRY are related only distantly and recognize different nucleotide sequences (Giese et al. 1992, 1994). Therefore, we consider it unlikely that the HMG domain of SRY mediates interactions with proteins that specifically recognize the TCR $\alpha$ enhancer, although we cannot rule out protein-protein contacts that involve a common feature of these structural motifs. We also attempted to replace the LEF-1-binding site in the TCR $\alpha$ enhancer with a 90-bp A-tract sequence, constituting an intrinsic bend of a similar magnitude to the LEF-induced DNA bend. The activity of this modified TCR $\alpha$ enhancer, however, was lower than that of an enhancer lacking a functional LEF-1-binding site, presumably because insertion of such a long A-tract disrupted the overall geometry of the TCR $\alpha$ enhancer (data not shown).

LEF-1 was shown previously to contain a context-dependent activation domain in the amino-terminal half of the protein, which is thought to mediate interactions with other enhancer-bound proteins (Carlson et al. 1993; Giese and Grosschedl 1993|. Although these putative protein-protein interactions may contribute to transcriptional stimulation in vivo, they do not participate in the assembly of the TCR $\alpha$ enhancer complex in vitro. The HMG domain of LEF-1, which bends the DNA helix, is sufficient for the formation of a stable multiprotein complex in vitro and can partially stimulate enhancer function in vivo. However, the activation domain is required for full stimulation of enhancer function by LEF1. Thus, the architectural role of LEF-1 in regulating the $\mathrm{TCR} \alpha$ enhancer may consist of both juxtaposing nonadjacent binding sites through DNA bending and position- ing the activation domain for interaction with other enhancer-bound proteins.

The formation of a stable nucleoprotein complex at the TCR $\alpha$ enhancer in a DNase I protection assay shows a marked dependence on the HMG domain of LEF-1 and on a specific helical phasing relationship of the nonadjacent LEF-1 - and ATF/CREB-binding sites. In contrast, the transcriptional effects of mutations in the TCR $\alpha$ enhancer that alter this helical phasing relationship are relatively modest. This can be interpreted to suggest that the architecture of proteins at the TCR $\alpha$ enhancer in vivo may be somewhat flexible. The dependence of TCR $\alpha$ enhancer function on LEF-1 in vivo may be influenced by the presence of abundant nonspecific DNAbending proteins and by modifications of proteins that alter the strength of protein-protein interactions. For example, the formation of a ternary complex between the Ets-protein Pu.1 and the nuclear factor NF-EM5 is increased markedly by phosphorylation of Pu.1 (Ponguballa et al. 1993). Strong interactions between proteins bound at nonadjacent sites may, in principle, diminish the requirements for a directed DNA bend induced by a sequence-specific protein and thus allow for functional substitution by nonspecific proteins that increase the flexibility of DNA. This view is supported by recent experiments indicating that the sequence-specific DNAbending protein IHF can be replaced, in part, by the nonspecific DNA-bending proteins HU and HMG-1 in the assembly of a higher-order nucleoprotein complex involved in site-specific recombination (Segall et al. 1994). Moreover, the formation of the specific multiprotein complex at the TCR $\alpha$ enhancer, which appears to involve one architectural component, may be more flexible than the nucleoprotein complexes assembled at the bacteriophage $\lambda$ att $P$ site and the $\beta$-interferon enhancer, which both use an architectural element at three distinct sites (Nash 1990; Thanos and Maniatis 1992; Du et al. 1993).

Recently, we examined the biological role of LEF-1 for lymphoid gene expression and mouse development by targeted inactivation of the $L E F-1$ gene in the mouse germ line (van Genderen et al. 1994). The LEF-1-deficient mice were found to die shortly after birth and to display severe defects in the formation of various nonlymphoid organs. However, no obvious deficiencies were detected in lymphoid cell populations of the mutant mice at birth. Moreover, expression of the TCR $\alpha$ gene in the thymus of newborn $L E F-1|-/-|$ mice appeared to be normal (R. Okamura and R. Grosschedl, unpubl.). This lack of an obvious phenotype in $T$ lymphocytes could be accounted for, in principle, by a redundancy of LEF-1 with the closely related $T$ cell factor- 1 (TCF-1), which is also expressed in $\mathrm{T}$ cells and contains a DNA-binding domain virtually identical to that found in LEF-1 (van de Wetering et al. 1991). TCF-1-deficient mice also express the TCR $\alpha$ gene but have a decreased number of thymocytes with an increased percentage of an immature cell population (Verbeek et al. 1995). Consistent with a redundant function of LEF-1 and TCF-1 in T cells, preliminary analysis of mice homozygous for a mutation in both genes 
revealed a more severe deficiency in the generation of mature $\mathrm{T}$ lymphocytes ( $\mathrm{R}$. Okamura, $\mathrm{H}$. Clevers, $\mathrm{R}$. Grosschedl, and S. Verbeek, unpubl.).

\section{Coordinate assembly and synergistic function of regulatory proteins in multiprotein complexes}

The assembly of proteins into a higher-order nucleoprotein complex may have important implications for the accuracy and diversity of transcriptional regulation. The selection of individual protein family members that share specificity of DNA recognition and protein-protein interactions may be augmented by a multiplicity of protein-protein contacts and by the cooperative nature of assembly of a multiprotein-DNA complex. For example, our data indicate that Ets-1, but not the closelyrelated Fli-1 protein, participates in the regulation of the TCR $\alpha$ enhancer, although both proteins have virtually identical DNA-binding specificities (Wang et al. 1992). Moreover, both Ets family members can interact with PEBP2 $\alpha$ to form a ternary complex at the TCR $\alpha$ enhancer. Although Ets-1 can associate with ATF-2 ${ }_{194}$, we were unable to detect such interaction with Fli-1 (data not shown). This result seems to imply that the PEBP $2 \alpha-$ Ets-1-DNA complex but not the PEBP2 $\alpha-F l i-1-D N A$ complex can be stabilized by association with an ATF/ CREB protein. Thus, multiple protein-protein contacts may be necessary to allow for the recruitment of a particular protein into a functional enhancer complex.

The formation of a higher-order multiprotein complex may also have an important role in stabilization of protein-DNA interactions. Stable occupancy of the PEBP2 $\alpha$ - and Ets-binding sites in a DNase I protection assay was only detected in the presence of LEF-1 and a specifically positioned nonadjacent ATF/CREB-binding site. In particular, the dependence on a specific helical phase of these factor-binding sites strongly suggests a functional interaction between an ATF/CREB protein and the PEBP2 $\alpha-E t s-1-D N A$ ternary complex. Although a stable TCR $\alpha$ enhancer complex was formed in HeLa cell nuclear extracts complemented with the lymphoidspecific proteins LEF-1, PEBP2 $\alpha$, and Ets-1, we were unable to generate such a nucleoprotein complex with purified ATF- $2_{195}$ or ATF- $2_{194}$ and these lymphoid-specific proteins. In association assays, we detect specific interaction between Ets- 1 and the ATF-2 ${ }_{194}$ isoform, which lacks part of the dimerization domain and is presumably a monomer, but not between Ets-1 and the dimeric ATF$2_{195}$ or CREB proteins (data not shown). This difference in the association potential of the ATF- $2_{195}$ and ATF$2_{194}$ proteins raises the interesting possibility that a change in the conformation of an ATF/CREB protein occurs within the context of the enhancer complex in nuclear extracts and exposes a surface for efficient association with Ets-1. According to this view, this interaction surface would be obscured in the recombinant ATF$2_{195}$ protein in solution. For example, phosphorylation is thought to alter the conformation of ATF-2 and increase its potential to interact with DNA and with other pro- teins (Abdel-Hafiz et al. 1992; Thanos et al. 1993). Alternatively, a cofactor in nuclear extracts may facilitate the association between ATF-2 and Ets-1. Consistent with this scheme, interactions between ATF-2 and the p50 subunit of $N F_{\kappa} B$ in the $\beta$-interferon enhancer were found to be augmented by HMG-I(Y) (Du et al. 1993). HMG-I(Y) bends DNA and, by inducing conformational changes in ATF-2, NFKB, and DNA, it may provide a structural component that facilitates DNA-protein and proteinprotein interactions (Thanos and Maniatis 1992; Du et al. 1993; Du and Maniatis 1994).

Whatever additional factors contribute to the formation of a TCR $\alpha$ enhancer complex, our data suggest that LEF-induced DNA bending and interactions between multiple proteins provide a mechanism to allow for specific recruitment of proteins to the enhancer and for stability of the final higher-order nucleoprotein complex. However, the stereospecific assembly of nucleoprotein complexes, such as those formed at the TCR $\alpha$ and $\beta$-interferon enhancers, may be restricted to small functional enhancer units. Regulatory regions that govern intricate developmental patterns of gene expression may consist of multiple such units that are flexible in their relationship to one another and to the promoter.

\section{Materials and methods \\ Cell culture, viral infections, and nuclear extract preparations}

COS-7 cells and HeLa cells were cultured at $37^{\circ} \mathrm{C}$ in Dulbecco's modified Eagle medium, supplemented with $10 \%$ fetal calf serum (FCS), and T cells (BW5147) and B cells (Namalwa) were grown in RPMI medium, supplemented with $10 \%$ FCS and 50 $\mu \mathrm{M}$ 2-mercaptoethanol. Infections of HeLa cells with recombinant vaccinia virus were performed as described in Travis et al. (1991). Nuclear extracts were prepared according to Dignam et al. $\{1983\}$.

\section{Plasmid construction}

The expression plasmids for full-length LEF-1 protein and the LEF-HMG domain peptide are described in Giese and Grosschedl (1993). The coding region for the SRY-HMG domain (Giese et al. 1992) was ligated into plasmid pCG, a pEVRF derivative (Matthias et al. 1989). The pCG plasmid contains the human cytomegalovirus (CMV) enhancer/promoter region, the translation initiation region of the herpes simplex virus (HSV) thymidine kinase $(t k)$ gene, and the sequence for the HAl epitope tag (SYPYDVPDYASLGGPS; Wilson et al. 1984) that was followed by a translation stop codon. The coding region for PEBP $2 \alpha$ was isolated from the PEBP $2 \alpha$ cDNA (Ogawa et al. 1993a) by restriction with FspI (amino acid 35) and EcoRI (amino acid 501) and ligated into the pCG plasmid. The coding region for the Runt domain of PEBP $2 \alpha$ was isolated from the PEBP $2 \alpha$ cDNA with $N$ coI (amino acid 95) and HindIII (amino acid 226), blunt-ended, and ligated into pGEX-2T cleaved with $S m a I$. The coding region of the PEBP $2 \beta$ protein was obtained by PCR |forward Nco primer 5'-CCATGGCGCGCGTCGTCCGGACC, reverse Xho primer 5'-CTCGAGTCTTGCTGTCTTCTTGC) using the PEBP2 $\beta$ cDNA (Ogawa et al. 1993b) as template. The amplified product was ligated into a NcoI-XhoI- 
cleaved pET23d vector, in-frame with a hexa-histidine tag. The Ets-1-coding region was generated by PCR (forward Nco primer 5'-CATGCCATGGAGGCGGCCGTCGATCTCAAG, reverse Bam primer 5'-GGATCCCGACCTTCGATGTCAGCATCCGGCTTTACATCC) using the Ets-1 cDNA (Chen 1990) as template and ligated into plasmid pEVRF. GST-Ets-l and GST-EtsHA were generated by fusion of the Ets-1 and Ets-HA-coding regions in-frame with the coding region of the GST gene in plasmid pGEX-3X (Pharmacia). The coding region of Fli-1 was generated by PCR (Xba primer 5'-TCTAGAATGTCGACCATGGACGGGACTATTAAGGAG, reverse Xho primer 5'CTCGAGGTAGTAGCTGCCTAAGTGTGA) using the Fli-1 cDNA (Ben-David et al. 1991) and ligated into plasmid pCG. The coding region for CREB was isolated by restriction digest of the CREB cDNA (Berkowitz and Gilman 1990) with NdeI and BamHI and ligated into plasmid pHB-40P, a pET derivative (Studier et al. 1990). GST-p85 is described in Klippel et al. (1993). ATF-2 $2_{195}$ is described in Du and Maniatis (1994). GSTATF- $2_{194}$ is an ATF- 2 isoform that lacks the DNA-binding and the dimerization domain. In this isoform, the nucleotide sequence CAGCTGCAG at the third leucine of the leucine zipper is fused to the sequence CTGCTGATA, 106 nucleotides downstream, which results in a frameshift and the addition of 40 amino acids. Escherichia coli K-12 strains DH5 $\alpha$ (Bethesda Research Laboratories) and BL21 (DE3)plysS (Studier et al. 1990) were used for plasmid propagation and for expression of proteins that are under the control of the lac or T7 promoter. The wildtype minimal TCR $\alpha$ enhancer construct, which contains the minimal fos promoter $\{-56$ to +109$\}$ linked to the chloramphenicol acetyltransferase (CAT) gene (Berkowitz et al. 1989), has been described previously (Travis et al. 1991). The sequences of mutated factor-binding sites in the Ml-M4 TCR $\alpha$ enhancer constructs, represented in lowercase letters, are shown together with the wild-type sequences. Construct $\mathrm{Ml}$, ATF/CREB [TtACcaCAT; TGACGTCA /wild type; Jones et al. 1988)]; construct M2, LEF-1 [aaTTTCAA; CCTTTGAA /wild type; Travis et al. 1991; Giese et al. 1991; 1992)]; construct M3, PEPB2a [aaGgt; CCGCA (wild type; Thornell et al. 1992)]; construct M4, Ets-1 [CACATggTg; CACATCCTC/wild type; Ho et al. 1990)]. In construct TCR $\alpha$ SRY, the following nucleotides in the LEF-1-binding site were substituted to generate the SRYbinding site (CCaTTGttc, CCTTTGAAG; Giese et al. 1992, 1994). Construct TCR $\alpha+4$ and TCR $\alpha+10$ contain insertions of 4 (CTTA) or 10 (CTAGCTAGCT) nucleotides at position 61 between the ATF/CREB- and LEF-1-binding sites in the minimal TCR $\alpha$ enhancer. Only the upper strand is given for the mutant TCR $\alpha$ enhancer constructs in which the order of the factor-binding sites (underlined) had been changed. Construct M5, PEPB2 $\alpha$ /ETS-1/ATF/CREB/LEF-1, 5'-TCCCGCAGAAGCCACATCCTCTGGAAAGAGGCGGTCCCCTCCCATTTCCATGACGTCATGGTTACCAAGAGGGGCAAGTAGGCACCCTTTGAAGCTC; construct M6, ATF/CREB/PEPB2 $\alpha$ / Ets-1/LEF-1，5'-GGCGGTCCCCTCCCATTTCCATGACGTCATGGTTACCAAGAGGGGCAATCCCGCAGAAGCCACATCCTCTGGAAAGAGTAGGGCACCCTTTGAAGCTC. The mutant TCR $\alpha$ enhancer constructs $M 7$ and $M 8$ contain nucleotide substitutions in the LEF-1-binding site as indicated in Figure 5A.

Ets-1 deletion constructs encoding amino acids 60-180, 60-240, and 60-300 were PCR amplified (forward primer 5'-CGACTGGGAATCCCCAAAGAC, reverse primers 5'CTAGAAGCTGGGCTCTGAGAACTC, 5'-TCATCTCCCCAGGCACATGTTGTC, 5'-TCAGGGCTTGTGGTTGGGCAGGGC, respectivelyl, and ligated into modified Bluescript vectors. Ets-1 deletion constructs lacking 123, 167, or 230 amino-terminal residues were generated by digestion of the
Ets-1 cDNA with EcoRV, SphI, or HpaI, respectively, and ligation of the Ets-1 DNA fragments into a modified Bluescript vector.

\section{Transient expression of recombinant proteins and} CAT assays

Transient DNA transfections into mammalian cells were performed as described in Grosschedl and Baltimore (1985) using the DEAE-dextran/chloroquine procedure with various amounts of effector and reporter DNA and a Rous sarcoma virus (RSV)-luciferase reporter plasmid (De Wet et al. 1987) as a measure of transfection efficiency. Cells were harvested and CAT activity analyzed as described in Giese and Grosschedl (1993).

\section{Immunoblotting, EMSA, and DNase I footprint analysis}

Immunoblotting was performed as described in Giese and Grosschedl (1993). DNase I footprint analysis was performed essentially as described in Travis et al. (1991). Briefly, the DNA probes were incubated in binding buffer [ $10 \mathrm{mM}$ HEPES ( $\mathrm{pH} 7.9$ ), $50 \mathrm{~mm} \mathrm{KCl}, 5 \mathrm{~mm} \mathrm{MgCl} 2,0.5 \mathrm{~mm}$ EDTA, $0.5 \mathrm{mM}$ spermidine, $10 \%$ glycerol] including $750 \mathrm{ng}$ of salmon sperm DNA and 750 $\mathrm{ng}$ of poly[d(I-C)] in the absence or presence of $100 \mu \mathrm{g}$ of nuclear extract from HeLa cells. Samples were treated with DNase I at $15 \mu \mathrm{g} / \mathrm{ml}$ for $90 \mathrm{sec}$, and the reactions were stopped by adding phenol. DNA samples were phenol extracted, ethanol precipitated, and analyzed by denaturing polyacrylamide gel electrophoresis. EMSAs were performed with $50 \mathrm{ng}$ of salmon sperm DNA and the indicated amounts of purified proteins according to Travis et al. (1991).

\section{Protein-protein interactions}

Bacterial cell lysates containing various overexpressed proteins were separated by $12 \%$ SDS-PAGE, blotted onto nitrocellulose membranes (Schleicher \& Schuell), and blocked for several hours at $4^{\circ} \mathrm{C}$ in TBST buffer [ $10 \mathrm{mM}$ Tris- $\mathrm{HCl}$ (pH 7.5), $130 \mathrm{~mm}$ sodium chloride, $0.5 \%$ Tween $20,0.2 \%$ sodium azide| containing $3 \%$ bovine serum albumin (BSA), $0.1 \mathrm{~mm}$ methionine, and $50 \mu \mathrm{g} / \mathrm{ml}$ ethidium bromide (EtBr). The nitrocellulose filters were incubated with in vitro-translated /reticulocyte lysates; Promega) ${ }^{35} \mathrm{~S}$-labeled proteins in TBST buffer containing cold methionine and $\mathrm{EtBr}$ for $12-16 \mathrm{hr}$ at $4^{\circ} \mathrm{C}$, and washed in TBST buffer; bound proteins were visualized by autoradiography. For protein association experiments on glutathione-agarose beads, GST-fusion proteins were overexpressed in bacteria and purified. Immobilized proteins were incubated with ${ }^{35} \mathrm{~S}$-labeled proteins in $200 \mu$ l of TBST buffer containing $0.2 \%$ BSA and EtBr $(50$ $\mu \mathrm{g} / \mathrm{ml}$ ) at room temperature for $30 \mathrm{~min}$. The agarose beads were washed with $3 \mathrm{ml}$ of TBST buffer, and associated proteins eluted by the addition of sample buffer $[0.125 \mathrm{~mm}$ Tris- $\mathrm{HCl}(\mathrm{pH} 6.8)$, $8 \%$ SDS, $20 \% \beta$-mercaptoethanol, and $40 \%$ glycerol]. Bound proteins were visualized after SDS-PAGE by autoradiography.

\section{Acknowledgments}

We thank Mike Gilman, Yoshiaki Ito, Anke Klippel, and Tom Maniatis for generously providing cDNA clones and expression plasmids. We thank Alexander Johnson and Bill Forrester for discussions and Laurakay Bruhn, Carol Gross, James Hagman, Howard Nash, and Keith Yamamoto for their helpful comments on the manuscript. This work was supported, in part, by funds of the Howard Hughes Medical institute and the National Institutes of Health. 
The publication costs of this article were defrayed in part by payment of page charges. This article must therefore be hereby marked "advertisement" in accordance with 18 USC section 1734 solely to indicate this fact.

\section{References}

Abdel-Hafiz, H., L. Heasley, J. Kyriakis, J. Avruch, D. Kroll, G. Johnson, and J. Hoeffler. 1992. Activation transcription factor-2 DNA-binding activity is stimulated by phosphorylation catalyzed by $\mathrm{p} 42$ and p54 microtubule-associated protein kinases. Mol. Endocrinol 6: 2079-2089.

Ben-David, Y., E. Giddens, K. Letwin, and A. Bernstein. 1991. Erythroleukemina induction by Friend murine leukemia virus: Insertional activation of a new member of the ets gene family, Fli-1, closely linked to c-ets-1. Genes \& Dev. 5: 908 918.

Berkowitz, L. and M. Gilman. 1990. Two distinct forms of active transcription factor CREB (CAMP response element binding protein|. Proc. Natl. Acad. Sci. 87: 5258-5262.

Berkowitz, L., K. Riabowol, and M. Gilman. 1989. Multiple elements of a single functional class are required for cyclic AMP responsiveness of the mouse c-fos promoter. Mol. Cell. Biol 9: 4272-4281.

Carlson, P., M. Waterman, and K. Jones. 1993. The hLEF/TCF$1 \alpha$ HMG protein contains a context-dependent transcriptional activation domain that induces the TCR $\alpha$ enhancer in T cells. Genes \& Dev. 7: 2418-2430.

Chen, J. 1990. Cloning, sequencing, and expression of mouse c-ets-1 cDNA in baculovirus expression system. Oncogene Res. 5: 277-285.

Dalton, S. and R. Treisman. 1992. Characterization of SAP-1, a protein recruited by serum response factor to the c-fos serum response element. Cell 61: 597-612.

De Wet, J., K. Wood, M. DeLuca, D. Helinski, and S. Subramani. 1987. Firefly luciferase gene: Structure and expression in mammalian cells. Mol. Cell. Biol. 7: 725-737.

Dignam, J., R. Lebovitz, and R. Roeder. 1983. Accurate transcription initiation by RNA polymerase II in a soluble extract from isolated mammalian nuclei. Nucleic Acids Res. 11: 1475-1489.

Du, W. and T. Maniatis. 1994. The high mobility group protein HMG $\mathrm{I}(\mathrm{Y})$ can stimulate or inhibit DNA binding of distinct transcription factor ATF-2 isoforms. Proc. Natl. Acad. Sci. 91: 11318-11322.

Du, W., D. Thanos, and T. Maniatis. 1993. Mechanisms of transcriptional synergism between distant virus-inducible enhancer elements. Cell 74: 887-898.

Echols, H. 1986. Multiple DNA-protein interactions governing high-precision DNA transactions. Science 233: 1050-1056.

Ferrari, S., V. Harley, A. Pontiggia, P. Goodfellow, R. LovellBadge, and M. Bianchi. 1992. SRY, like HMGl, recognizes sharp angles in DNA. EMBO J. 11: 4497-4506.

Georgopoulos, K., B. Morgan, and D. Moore. 1992. Functionally distinct isoforms of the CRE-BP DNA-binding protein mediate activity of a T-cell-specific enhancer. Mol. Cell. Biol. 12: $747-757$.

Giese, K. and R. Grosschedl. 1993. LEF-1 contains an activation domain that stimulates transcription only in a specific context of factor-binding sites. EMBO J. 12: 4667-4676.

Giese, K., A. Amsterdam, and R. Grosschedl. 1991. DNA-binding properties of the HMG domain of the lymphoid-specific transcriptional regulator LEF-1. Genes \& Dev. 5: 2567-2578.

Giese, K., J. Cox, and R. Grosschedl. 1992. The HMG domain of lymphoid enhancer factor 1 bends DNA and facilitates as- sembly of functional nucleoprotein structures. Cell 69: 185195.

Giese, K., J. Pagel, and R. Grosschedl. 1994. Distinct DNAbinding properties of the high mobility group domain of murine and human SRY sex-determining factors. Proc. Natl. Acad. Sci. 91: 3368-3372.

Grosschedl, R. and D. Baltimore. 1985. Cell-type specificity of immunoglobulin gene expression is regulated by at least three DNA sequence elements. Cell 41: 885-897.

Grosschedl, R., K. Giese, and J. Pagel. 1994. HMG domain proteins: Architectural elements in the assembly of nucleoprotein structures. Trends Genet. 10: 94-100.

Gunther, C. and B. Graves. 1994. Identification of ETS domain proteins in murine $\mathrm{T}$ lymphocytes that interact with the moloney murine leukemia virus enhancer. Mol. Cell. Biol. 14: 7569-7580.

Hai, T., F. Liu, W. Coukos, and M. Green. 1990. Transcription factor ATF cDNA clones: An extensive family of leucine zipper proteins able to selectively form DNA binding heterodimers. Genes \& Dev. 3: 2083-2090.

Herr, W. and J. Clarke. 1986. The SV40 enhancer is composed of multiple functional elements that can compensate for one another. Cell 45: 461-470.

Herskowitz, I. 1990. A regulatory hierarchy for cell specialization in yeast. Nature 342: 749-757.

Hill, C., R. Marais, S. John, J. Wynne, S. Dalton, and R. Treisman. 1993. The SRF accessory protein Elk-l contains a growth factor-regulated transcriptional activation domain. Cell 73: 395-406.

Ho, I. and J. Leiden. 1990. Regulation of the human T-cell receptor $\alpha$ gene enhancer: Multiple ubiquitous and T-cell-specific nuclear proteins interact with four hypomethylated enhancer elements. Mol. Cell. Biol. 10: 4720-4727.

Ho, I., L. Yang, G. Morle, and J. Leiden. 1989. A T-cell specific transcriptional enhancer element $3^{\prime}$ of the $\mathrm{C} \alpha$ in the human T-cell receptor $\alpha$ locus. Proc. Natl. Acad. Sci. 86: 6714-6718.

Ho, I, N. Bhat, L. Gottschalk, T. Lindsten, C. Thompson, T. Papas, and J. Leiden. 1990. Sequence-specific binding of human Ets- 1 to the $\mathrm{T}$ cell receptor $\alpha$ gene enhancer. Science 250: 814-817.

Hoey, T., R. Weinzierl, G. Gill, J. Chen, B. Dynlacht, and R. Tjian. 1993. Molecular cloning and functional analysis of Drosophila TAF110 reveal properties expected of coactivators. Cell 72: 247-260.

Hoover, T., E. Santero, S. Porter, and S. Kustu. 1990. The integration host factor stimulates interaction of RNA polymerase with NIFA, the transcription activator for nitrogen fixation operons. Cell 63: 11-22.

Janknecht, R. and A. Nordheim. 1992. Elk-l protein domains required for direct and SRF-assisted DNA-binding. Nucleic Acids Res. 20: 3317-3324.

Johnson, P. and S. McKnight. 1989. Eukaryotic transcriptional regulatory proteins. Annu. Rev. Biochem. 58: 799-839.

Jones, N., P. Rigby, and E. Ziff. 1988. Trans-acting protein factors and the regulation of eukaryotic transcription: Lessons from studies on DNA tumor viruses. Genes \& Dev. 2: 267281.

Kagoshima, H., K. Shigesada, M. Satake, Y. Ito, H. Miyoshi, M. Ohki, M. Pepling, and P. Gergen. 1993. The runt domain identifies a new family of heteromeric transcriptional regulators. Trends Genet. 9: 338-341.

Karim, F., L. Urness, C. Thummel, M. Klemsz, S. McKercher, A. Celada, C. Van Beveren, R. Maki, C. Gunther, J. Nye, and B. Graves. 1990. The ets-domain: A new DNA-binding motif that recognizes a purine-rich core DNA sequence. Genes \& Dev. 4: 1451-1453. 
Kim, J., D. Nikolov, and S. Burley. 1993. Co-crystal structure of TBP recognizing the minor groove of a TATA element. $\mathrm{Na}$ ture 365: 520-527.

Kim, Y., J. Geiger, S. Kahn, and P. Sigler. 1993. Crystal structure of a yeast TBP/TATA-box complex. Nature 365: 512-520.

Klippel, A., J. Escobedo, M. Hirano, and L. Williams. 1993. The interaction of small domains between the subunits of phosphatidylinositol 3-kinase determines enzyme activity. Mol. Cell. Biol. 13: 5560-5566.

Lai, J. and W. Herr. 1992. Ethidium bromide provides a simple tool for identifying genuine DNA-independent protein associations. Proc. Natl. Acad. Sci. 89: 6958-6962.

Landsman, D. and M. Bustin. 1993. A signature for the HMG-1 box DNA-binding proteins. BioEssays 15: 539-546.

Lim, F., N. Kraut, J. Frampton, and T. Graf. 1992. DNA binding by c-Ets-1, but not v-Ets-1, is repressed by an intramolecular mechanism. EMBO J. 11: 643-652.

Lin, Y. and M. Green. 1991. Mechanism of action of an acidic transcriptional activator in vitro. Cell 64: 971-981.

Lin, S. and A. Riggs. 1975. The general affinity of lac repressor for E. coli DNA: Implications for gene regulation in procary. otes and eucaryotes. Cell 4: 107-111.

Matthias, P., M. Mueller, E. Schreiber, S. Rusconi, and W. Schaffner. 1989. Eukaryotic expression vectors for the analysis of mutant proteins. Nucleic Acids Res. 17: 6418.

Maekawa, T., H. Sakura, C. Kanei-Ishii, T. Sudo, T. Yoshimora, J. Fujisawa, M. Yoshida, and S. Ishii. 1989. Leucine zipper structure of the protein CRE-BPl binding to the CAMP response element in the brain. EMBO I. 8: 2023-2028.

Natesan, S. and M. Gilman. 1993. DNA bending and orientation dependent function of YY1 in the c-fos promoter. Genes \& Dev. 7: 2497-2509.

Nash, H. 1990. Bending and supercoiling of DNA at the attachment site of bacteriophage lambda. Trend Biochem. Sci 15: 222-227.

Ogawa, E., M. Maruyama, H. Kagoshima, M. Inuzuka, J. Lu, M. Satake, K. Shigesada, and Y. Ito. 1993a. PEBP2/PEA2 represents a family of transcription factors homologous to the products of the Drosophila runt gene and the human $A M L 1$ gene. Proc. Natl. Acad. Sci. 90: 6859-6863.

Ogawa, E., M. Inuzuka, M. Maruyama, M. Satake, M. NaitoFujimoto, Y. Ito, and K. Shigesada. 1993b. Molecular cloning and characterization of PEBP2 $\beta$, the heterodimeric partner of a novel Drosophila runt-related DNA binding protein PEBP2 $\alpha$. Virology 194: 314-331.

Ponguballa, J., C. Van Beveren, S. Nagulapalli, M. Klemsz, S. McKercher, R. Maki, and M. Atchison. 1993. Effect of Pu.l phosphorylation on interaction with NF-EM5 and transcriptional activation. Science 259: 1622-1625.

Ptashne, M. 1986. A genetic switch. Cell Press/Blackwell Scientific, Cambridge/Boston, MA, respectively.

Schleif, R. 1992. DNA looping. Annu. Rev. Biochem 61: 199224.

Segall, A., S. Goodman, and H. Nash. 1994. Architectural elements in nucleoprotein complexes: Interchangeability of specific and nonspecific DNA binding proteins. $E M B O /$. 13: $4536-4548$.

Shore, D. and R. Baldwin. 1983. Energetics of DNA twisting. I. Mol. Biol. 170: 957-981.

Starr, D. and D. Hawley. 1991. TFIID binds in the minor groove of the TATA box. Cell 67: 1231-1240.

Studier, F., A. Rosenberg, J. Dunn, and J. Dubendorff. 1990. Use of T7 RNA polymerase to direct expression of cloned genes. Methods Enzymol. 185: 60-89.

Thanos, D. and T. Maniatis. 1992. The high mobility group protein $\mathrm{HMGI}(\mathrm{Y})$ is required for NF-кB-dependent virus in- duction of the human IFN- $\beta$ gene. Cell 71: 777-789.

Thanos, D., W. Du, and T. Maniatis. 1993. The high mobility group protein $\mathrm{HMG} \mathrm{I}(\mathrm{Y})$ is an essential structural component of a virus-inducible enhancer complex. Cold Spring Harbor Symp. Quant. Biol. 58: 73-81.

Thornell, A., B. Hallberg, and T. Grundstrom. 1992. Binding of SL3-3 enhancer factor 1 transcriptional activators to viral and chromosomal enhancer sequences. J. Virol. 65: 42-50.

Tjian R. and T. Maniatis. 1994. Transcriptional activation: A complex puzzle with few easy pieces. Cell 77: 5-8.

Travis, A., A. Amsterdam, C. Belanger, and R. Grosschedl. 1991. LEF-1, a gene encoding a lymphoid-specific protein with an HMG domain regulates T-cell receptor $\alpha$ enhancer function. Genes \& Dev. 5: 880-894.

Van de Wetering, M., M. Oosterwegel, D. Dooijes, and H. Clevers. 1991. Identification and cloning of TCF-1, a lymphocytespecific transcription factor containing a sequence-specific HMG-box. EMBO /. 10: 123-132.

Van Genderen, C., R. Okamura, I. Farinas, R. Quo, T. Parslow, L. Bruhn, and R. Grosschedl. 1994. Development of several organs that require inductive epithelial-mesenchymal interactions is impaired in LEF-1 deficient mice. Genes \& Dev. 8: 2691-2703.

Verbeek, S., D. Izon, F. Hofhuls, E. Robanus-Maandag, H. te Riele, M. van de Wetering, M. Oosterwegel, A. Wilson, R.H. MacDonald, and H. Clevers. 1995. An HMG-box-containing T-cell factor required for thymocyte differentiation. Nature 374: 74-80.

Wang, C., B. Petryniak, I. Ho, C. Thompson, and J. Leiden. 1992. Evolutionary conserved Ets family members display distinct DNA binding specificities. I. Exp. Med. 175: 1391-1399.

Wang, J. and G. Giaever. 1988. Action at a distance along a DNA. Science 240: 300-304.

Wang, S., Q. Wang, B. Crute, I. Melnikova, S. Keller, and N. Speck. 1993. Cloning and characterization of subunits of the $\mathrm{T}$-cell receptor and murine leukemia virus enhancer corebinding factor. Mol. Cell. Biol. 13: 3324-3339.

Waterman, M., and K. Jones. 1990. Purification of TCF- $1 \alpha$, a T cell-specific transcription factor that activates the $\mathrm{T}$-cell receptor $\mathrm{C} \alpha$ gene enhancer in a context-dependent manner. New Biol. 2: 621-636.

Waterman, M., W. Fischer, and K. Jones. 1991. A thymus-specific member of the HMG protein family regulates the human T cell receptor alpha enhancer. Genes \& Dev. 5: 656669.

Wilson, I, H. Niman, R. Hougten, A. Cherenson, M. Conolly, and R. Lerner. 1984. The structure of an antigen determinant in a protein. Cell 37: 767-778.

Winoto, A. and D. Baltimore. 1989. A novel, inducible and T cell-specific enhancer located at the $3^{\prime}$ end of the $T$ cell receptor a locus. EMBO I. 8: 729-733.

Wotton, D., J. Ghysdael, S. Wang, N. Speck, and M. Owen. 1994. Cooperative binding of Ets-1 and core binding factor to DNA. Mol. Cell. Biol. 14: 840-850.

Yang, C. and H. Nash. 1989. The interaction of E. coli IHF protein with its specific binding sites. Cell 57: 869-880. 


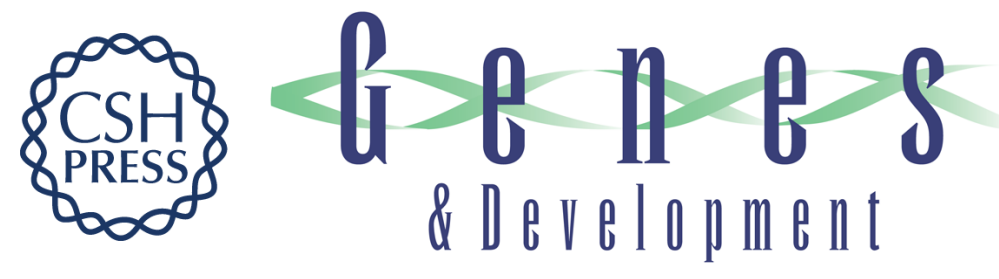

\section{Assembly and function of a TCR alpha enhancer complex is dependent on LEF-1-induced DNA bending and multiple protein-protein interactions.}

K Giese, C Kingsley, J R Kirshner, et al.

Genes Dev. 1995, 9:

Access the most recent version at doi:10.1101/gad.9.8.995

References This article cites 72 articles, 29 of which can be accessed free at: http://genesdev.cshlp.org/content/9/8/995.full.html\#ref-list-1

License

Email Alerting Service

Receive free email alerts when new articles cite this article - sign up in the box at the top right corner of the article or click here.

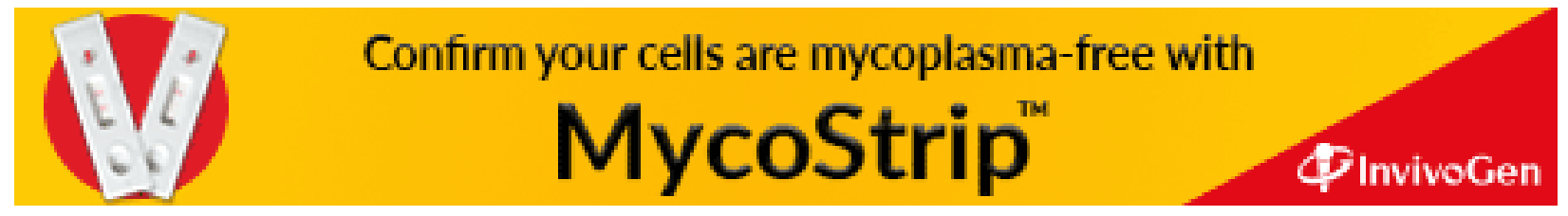

